\title{
Fitossociologia de um Cerrado denso em área de influência de torre de fluxo de carbono, Pé-de-Gigante, Parque Estadual de Vassununga, SP
}

\author{
Sabrina Ribeiro Latansio-Aidar ${ }^{1}$, Ana Claudia Pereira de Oliveira ${ }^{2}$, \\ Humberto Ribeiro da Rocha ${ }^{3}$ \& Marcos Pereira Marinho Aidar ${ }^{4,5}$ \\ ${ }^{1}$ Pós-Graduação em Biodiversidade e Meio Ambiente, \\ Instituto de Botânica de São Paulo - IBt, Secretaria do Meio Ambiente - SMA \\ CP 4005, CEP 01061-970, São Paulo, SP, Brasil \\ ${ }^{2}$ Laboratório de Ecologia e Restauração Florestal, Departamento de Ciências Biológicas, \\ Universidade de São Paulo - USP, \\ Av. Pádua Dias, 11, CP 9, CEP 13418-900 Piracicaba, SP, Brasil \\ ${ }^{3}$ Instituto de Astronomia, Geofísica e Ciências Atmosféricas, Universidade de São Paulo - USP \\ Rua do Matão, 1226, Cidade Universitária, CEP 05508-090 São Paulo, SP, Brasil \\ ${ }^{4} \mathrm{PqC}$ IV, Seção de Fisiologia e Bioquímica de Plantas, Instituto de Botânica - IBt, \\ Secretaria do Meio Ambiente - SMA, \\ CP 4005, CEP 01061-970, São Paulo, SP, Brasil \\ ${ }^{5}$ Autor para correspondência: Marcos Pereira Marinho Aidar,e-mail: maidar@uol.com.br
}

LATANSIO-AIDAR, S.R., OLIVEIRA, A.C.P., ROCHA, H.R. \& AIDAR, M.P.M. Phytossociology of a dense Cerrado on the footprint of a carbon flux tower, Pé-de-Gigante, Vassununga State Park, SP. Biota Neotrop. 10(1): http://www.biotaneotropica.org.br/v10n1/en/abstract?inventory+bn00210012010.

\begin{abstract}
The Cerrado vegetation covers the Brazilian central areas (core area) which include extensive and continuous areas in the central States and some marginal areas in other States, including São Paulo, accounting originally for $21 \%$ of Brazilian territory. Nowadays, the remnants are $21,6 \%$ of its original coverage. About of $14 \%$ of the São Paulo State territory was originally covered with Cerrado vegetation, and today remnants account for less than $1 \%$ of the original distribution. Recent studies indicate that the net productivity in the Pé-de-Gigante Cerrado constitutes a small carbon sink, with seasonality playing a major role. The carbon flux studies in terrestrial ecosystems have rarely been accompanied by ecophysiological studies in order to explore the functional relationships among species, ecosystem and the values achieved. Therefore, our objectives were to characterize the vegetation structure in the meteorological and flux tower footprint. The flux tower allows studies related to long term measurements and dynamics of water, solar energy and $\mathrm{CO}_{2}$ fluxes in Cerrado vegetation. Plots $(10 \times 10 \mathrm{~m})$ were established in 0.2 ha area of Cerrado and all vascular plants with stem perimeter at ground level $\geq 6 \mathrm{~cm}$ (except vines and dead individuals) were sampled. The distribution of diameter classes and vertical structure, as well as the phytosociological parameters were analyzed. We recorded 1,451 individuals, distributed in 85 species belonging to 31 different families. The absolute density and the basal area were 7,255 ind.ha ${ }^{-1}$ and $7.9 \mathrm{~m}^{2} . \mathrm{ha}^{-1}$, respectively. Leguminosae showed the highest number of species (13). The Shannon's Index was 3.27. The distribution of diameter classes showed a curve in inverted " $\mathrm{J}$ ", most of the individuals being in the initial classes. We concluded that the area must be classified as dense Cerrado, mainly due to Anadenanthera falcata dominance, which occurrence in São Paulo State was reported only in rich soil sites in Cuestas Basaltic regions and also due to major basal area of these individuals, comparing with other Cerrado vegetation sites. A. falcata, Myrcia lingua and Xylopia aromatica showed the highest IVI (Importance value index).

Keywords: Anadenanthera falcata, basal area, Basaltic Cuestas, importance value index, Leguminosae, Santa Rita do Passa Quatro.
\end{abstract}

LATANSIO-AIDAR, S.R., OLIVEIRA, A.C.P., ROCHA, H.R. \& AIDAR, M.P.M. Fitossociologia de um Cerrado denso em área de influência de torre de fluxo de carbono, Pé-de-Gigante, Parque Estadual de Vassununga, SP. Biota Neotrop.10(1): http://www.biotaneotropica.org.br/v10n1/pt/abstract?inventory+bn00210012010.

Resumo: O domínio do Cerrado compreende uma área contínua nos estados centrais do Brasil e áreas disjuntas em outros estados, incluindo São Paulo. Essa vegetação ocupava originalmente $21 \%$ do território brasileiro, restando atualmente apenas $21,6 \%$ de sua extensão original. A área recoberta por essa vegetação em São Paulo cobria $14 \%$ de sua área total e seus remanescentes recobrem menos de $1 \%$ da ocorrência original dessa vegetação. Estudos recentes indicam que o valor da produtividade líquida no Cerrado Pé-de-Gigante (SP) constitui um pequeno dreno de carbono e indicou que a sazonalidade foi o fator determinante do valor observado. Os estudos dos fluxos de carbono em ecossistemas terrestres são raramente acompanhados de abordagens ecofisiológicas de modo a explorar a relação funcional das espécies que compõem o ecossistema e os valores líquidos obtidos para o mesmo. Assim, o objetivo deste trabalho foi caracterizar estruturalmente a vegetação presente na área de maior influência da torre de fluxo instalada no Cerrado Pé-de-Gigante, visando possibilitar estudos relacionados 
à quantificação em longo prazo da dinâmica dos fluxos de água, energia e $\mathrm{CO}_{2}$ na vegetação de Cerrado. Para isso foram levantadas 20 parcelas $(10 \times 10 \mathrm{~m}) \mathrm{em} 0,2$ ha de Cerrado, e amostraram-se todas as plantas com perímetro ao nível do solo $\geq 6 \mathrm{~cm}$ (exceto lianas e árvores mortas). A distribuição das classes de diâmetro e estrutura vertical, assim como os parâmetros fitossociológicos foram analisados. Encontramos 1451 indivíduos, distribuídos em 85 espécies, 52 gêneros e 31 famílias. A densidade absoluta e área basal foram de 7255 ind. ha ${ }^{-1}$ e de $7,9 \mathrm{~m}^{2} . \mathrm{ha}^{-1}$, respectivamente. A família Leguminosae apresentou o maior número de espécies (13). O Índice de diversidade de Shannon (H') foi 3,27 nats.ind" ${ }^{-1}$. A distribuição em classes de diâmetro mostrou uma curva de "J" invertido, estando a maioria dos indivíduos na primeira classe. Concluímos que a área deve ser classificada como Cerrado denso, devido principalmente à dominância pela espécie arbórea Anadenanthera falcata, cuja ocorrência no estado foi relatada apenas em locais com solos ricos em saturação de bases na região das Cuestas Basálticas, devido também à maior área basal dos indivíduos, comparando com outros fragmentos de Cerrado. Além da espécie citada, Myrcia lingua e Xylopia aromatica, apresentaram os maiores IVI (Valor de importância).

Palavras-chave: Anadenanthera falcata, área basal, Cuestas basálticas, índice de valor de importância, Leguminosae, Santa Rita do Passa Quatro.

\section{Introdução}

O Brasil é um dos países mais ricos em biodiversidade vegetal, onde são encontradas grandes formações, dentre estas a savana tropical brasileira (Cerrado) (Coutinho 2006). Sua localização geográfica é condicionada por fatores climáticos, tais como temperatura, precipitação, umidade do ar e tipo de substrato (Ribeiro \& Walter 1998).

O domínio do Cerrado, correspondente às "Oréades" no sistema de Martius (Joly et al. 1999) compreende uma extensa área contínua nos estados centrais do Brasil, algumas áreas marginais nos estados nordestinos e Amazonas e também áreas disjuntas em São Paulo e Paraná (Ratter et al. 1997). Originalmente esse domínio ocupava $21 \%$ da área territorial do Brasil (mais de 2 milhões de $\mathrm{km}^{2}$ ) e atualmente restam 21,6\% de sua extensão original (Conservation International 2009).

No estado de São Paulo, o Cerrado apresenta-se na forma de manchas dispersas, associado a solos de baixa fertilidade, especialmente na Depressão Periférica e no Planalto Ocidental Paulista (Ratter et al. 1997). A área recoberta por esta formação vegetal no estado correspondia originalmente a aproximadamente $14 \%$ da área total do estado (São Paulo 1997), tendo sido reduzida para 13,7\% em 1962 (Borgonovi \& Chiarini 1965), 4,2\% em 1973 (Serra Filho et al. 1975) e apenas 0,96\% em 1997 (Kronka et al. 1998).

O Cerrado é considerado a mais rica savana do planeta, provavelmente conseqüência da sua enorme antiguidade, cuja origem remonta o período Cretáceo (145 a 65 milhões de anos). A partir deste período experimentou longa evolução no decorrer do Terciário e grande especiação durante os períodos glaciais e interglaciais do Quaternário (Oliveira Filho \& Ratter 1995). Caracteriza-se por extrema complexidade em termos estruturais da vegetação (Oliveira-Filho et al. 1989), riqueza em espécies lenhosas endêmicas, perenifólias, brevidecíduas e decíduas (Moraes \& Prado 1998, Franco 2002, Paula 2002). Aspectos estes que, associados às graves ameaças sobre seus recursos naturais e à perda de mais de $70 \%$ da sua distribuição original (http://www.biodiversityhotspots.org) levaram à inclusão do Cerrado brasileiro como uma das áreas prioritárias para a conservação da biodiversidade (Myers et al. 2000).

Os estudos sobre a florística das vegetações de Cerrado no estado de São Paulo permaneceram por muitos anos estagnados, uma vez que a maioria dos trabalhos concentrava-se na região central do Brasil (Leitão-Filho 1992, Felfili et al. 1997). Foi a partir do trabalho de Eiten (1963), que evidenciou uma diversidade considerável dessa flora no estado e do crescente processo de devastação desse ecossistema, que os esforços no estudo da porção meridional de ocorrência dessa vegetação foram estimulados. Nesse processo, muitos estudos foram realizados sobre aspectos fitogeográficos, fisionômicos, florísticos e fitossociológicos (Leitão-Filho 1992, Ratter \& Dargie 1992, Castro et al. 1997, Castro et al. 1999, Batalha \& Mantovani 2000, Batalha et al. 2001, Ratter et al. 2003, Brando \& Durigan 2004).

Entretanto há pouca informação disponível sobre alterações estruturais na vegetação (Felfili et al. 2000), sendo este tipo de estudo restrito a poucas áreas em São Paulo (Silberbauer-Gottsberger \& Eiten 1983) e Brasília (Felfili et al. 2000, Henriques \& Hay 2002).

Dentre os muitos levantamentos fitossociológicos realizados no estado de São Paulo (Eiten 1963, Silberbauer-Gottsberger \& Eiten 1983, Leitão-Filho 1992, Batalha et al. 2001, Durigan et al. 2002, Brando \& Durigan 2004, Gomes et al. 2004, Pinheiro 2008), cinco trabalhos foram feitos na área do presente estudo (Castro 1987, Batalha \& Mantovani 2000, Batalha et al. 2001, Weiser \& Godoy 2001, Fidelis \& Godoy 2003), focando a florística e a fitossociologia. No entanto, ainda existem lacunas a serem preenchidas, especialmente no que se refere à diversificação dessa vegetação no estado de São Paulo, verificada por Durigan et al. (2003, 2004), que indicam a necessidade de esforço para melhor conhecimento dos remanescentes de Cerrado da porção meridional do Brasil.

Atualmente muita atenção vem sendo dada à contribuição potencial dos ecossistemas temperados e tropicais na incorporação líquida do $\mathrm{CO}_{2}$ de origem antropogênica pelos ecossistemas terrestres (Lloyd 1999, Malhi et al. 1999, Schulze et al. 1999). Fluxos de energia, água e carbono, avaliados por meio de técnicas de co-variação de vórtices turbulentos do dossel podem ser utilizados para a estimativa das respostas fotossintéticas líquidas de ecossistemas, assim como do balanço anual de carbono, em resposta às variações nas condições ambientais (Rocha et al. 2002).

Entretanto, essas avaliações são ainda muito limitadas em savanas, apesar de estas cobrirem cerca de um quinto da superfície terrestre (Vourlitis et al. 2001, Veenendall et al. 2004). Segundo Grace et al. (2006), as savanas tropicais podem ser bastante produtivas, com uma produtividade primária líquida (PPL) variando de 1 a 12 tC.ha-1/ano, cerca de $30 \%$ da produtividade primária bruta terrestre. As savanas encontram-se sob intensa pressão antrópica, e a taxa de perda pode exceder $1 \%$ ao ano, aproximadamente o dobro da taxa estimada para as florestas tropicais, constituindo desse modo, um fluxo para 
atmosfera potencialmente tão grande quanto o que é originado do desflorestamento de florestas tropicais (Machado et al. 2004).

Rocha et al. (2002) indicaram que o valor da PPL no Cerrado paulista Pé-de-Gigante constitui um pequeno dreno de carbono (0,1 \pm 0,3 tC. ha h $^{-1} /$ ano), similar ao valor encontrado para um Cerrado no Planalto Central do Brasil (Miranda et al. 1997), sugerindo que a sazonalidade é o fator determinante na resposta observada, pois induz a senescência foliar com conseqüente redução na atividade fotossintética e queda da produtividade durante a estação seca.

Esses estudos de fluxos de carbono em ecossistemas terrestres têm sido raramente acompanhados de abordagens ecofisiológicas de modo a explorar a relação funcional das espécies que compõem o ecossistema e os valores líquidos obtidos para o mesmo. Segundo Buchmann (2002), apenas 14\% de todos os estudos de covariação de vórtices turbulentos em florestas incluíram avaliações ecofisiológicas e/ou estimativas de biomassa, e nenhuma avaliação desse tipo foi feita até o momento em savanas. Diante dessa necessidade, uma combinação dessas diferentes abordagens é fortemente recomendada para uma melhor compreensão das dinâmicas dos fluxos associados ao funcionamento do ecossistema, assim, esse é um dos principais objetivos do Projeto no qual este estudo se insere (Projeto Biota/ Fapesp Interação Biosfera-Atmosfera Fase 2: Cerrados e Mudanças de Uso da Terra).

No contexto do Projeto mencionado, o foco do presente trabalho refere-se à caracterização florística e fitossociológica da vegetação de Cerrado presente na área de influência da torre micrometeorológica e de fluxos (AITm) instalada na Gleba Pé-de-Gigante, uma vez que os resultados obtidos pela torre serão aplicáveis para esse tipo de cobertura vegetal, e a integração de escalas no âmbito do Projeto só será possível com base no conhecimento da estrutura e composição dessa vegetação.

\section{Material e Métodos}

\section{1. Área de estudo}

A área de estudo (Gleba Pé-de-Gigante) localiza-se no Parque Estadual de Vassununga (entre $21^{\circ} 36-38^{\prime}$ S e $47^{\circ} 36-39^{\prime}$ O), Santa Rita do Passa Quatro, São Paulo, com área de 1.225 ha e altitude de 590 a $740 \mathrm{~m}$ (Batalha et al. 2001). O clima da região enquadra-se na categoria Cwag de Köppen (1948), ou seja, temperado, macrotérmico, moderadamente chuvoso e com inverno seco não rigoroso. A estação seca dura de maio a agosto e a estação úmida, de setembro a abril, com precipitação média anual de $1.499 \mathrm{~mm}$ e temperatura média anual de $21,5^{\circ} \mathrm{C}$ (Batalha \& Mantovani 2000). Os dados normais de 30 anos (1941-1970) calculados para a estação climatológica do DAEE em Santa Rita do Passa Quatro indicaram déficit hídrico para os meses de abril a setembro (Pires Neto et al. 2005). Predominam na área solos do tipo Latossolo Vermelho-Amarelo (Neossolo Quartzarênico órtico típico álico) (Pivello et al. 1998, Cooper et al. 2005). Uma caracterização detalhada da área pode ser encontrada em Pivello \& Varanda (2005).

No ano de avaliação (2006) os dados meteorológicos da estação mais próxima da área, São Simão (IAC; $21^{\circ} 29^{\prime} \mathrm{S}$ e $47^{\circ} 33^{\prime} \mathrm{O}$ ), indicam o total de precipitação de $1.412 \mathrm{~mm}$ sendo que em cinco meses a precipitação foi menor que $50 \mathrm{~mm}$ (abril a agosto), com temperatura média anual de $23,3{ }^{\circ} \mathrm{C}$, média máxima de $31,4{ }^{\circ} \mathrm{C}$ e mínima de $15,3^{\circ} \mathrm{C}$.

A estrutura, a composição e a diversidade de espécies que compõem o Cerrado sensu lato da área de estudo já foram estudadas por vários autores (Batalha \& Mantovani 2000, Batalha et al. 2001, Weiser \& Godoy 2001, Fidelis \& Godoy 2003) sendo encontrado Cerrado sensu stricto em cerca de $80 \%$ da área.

\section{Definição do AITm da torre meteorológica e de fluxo na área de estudo e levantamento fitossociológico}

A escolha da área de trabalho, ou AITm [região da superfície do solo que as avaliações representam segundo Finnigan (2004) ou o "campo de visão" dos instrumentos da torre, de acordo com Schmid (2002)], foi baseada na predominância, direção e intensidade do vento conforme definida por Rocha et al. $(2002,2005)$ e localizase entre $300-400 \mathrm{~m}$ da torre em direção leste $\left(110^{\circ}\right.$ geográficos) (Figura 1).

Nessa região foi demarcada uma transecção de $20 \times 100$ m ( 0,2 ha) que constituiu a área de levantamento fitossociológico, composta por 20 subparcelas de $10 \times 10 \mathrm{~m}$ demarcadas com estacas de alumínio e cordas de náilon. Como sugerido por Felfili et al. (2005), a unidade amostral mínima para parcelas de Cerrado é de 0,1 ha. Assim, a área do presente estudo correspondeu a área de duas unidades amostrais recomendadas. $\mathrm{O}$ critério de inclusão dos indivíduos foi o perímetro maior ou igual a $6 \mathrm{~cm}$, a $10 \mathrm{~cm}$ acima do nível do solo (exceto lianas e árvores mortas). O levantamento incluiu numeração, mapeamento e mensuração de todos os indivíduos da amostra, e a altura das plantas foi estimada com auxílio de vara telescópica.

A identificação das espécies foi realizada em campo e por meio de coletas de material botânico para posterior herborização e identificação por comparação em herbário ou envio a especialistas. As amostras botânicas coletadas foram depositadas no herbário da Esalq/ USP (ESA). Os nomes botânicos apresentados foram conferidos com a nomenclatura adotada pelo Missouri Botanical Garden (2009).

Os parâmetros fitossociológicos foram estimados segundo Martins (1993), os índices de diversidade florística da comunidade de Shannon (H') $\left(\log _{2}\right.$; nats.ind $\left.{ }^{-1}\right)$ segundo Weaver \& Shannon (1949) e Magurran (1988), o índice de equabilidade de Pielou (J) segundo Pielou (1975) e o índice de Morisita segundo Morisita (1954). Os parâmetros fitossociológicos foram estimados com uso do aplicativo FITOPAC desenvolvido pelo Dr. George Shepherd, Departamento de Botânica da Universidade de Campinas - UNICAMP (Shepherd 1995).

Além disso, para uma melhor análise da estrutura da vegetação na área de estudo através da comparação com outros estudos realizados no mesmo Cerrado do presente estudo (Castro 1987, Batalha \& Mantovani 2000, Weiser \& Godoy 2003, Fidelis \& Godoy 2003), foram elaborados histogramas de frequiência em classes de diâmetro (classes fixas de 4,5 cm) e altura (com intervalo de $2 \mathrm{~m}$ ) para as espécies de maior IVI, e obtidas as razões “q” de Liocourt (Meyer 1952), por meio da divisão do número de indivíduos em uma classe pelo número de indivíduos da classe anterior. Esta razão, quando constante, indica uma distribuição balanceada de diâmetros na comunidade.

\section{Resultados}

Foram encontrados 1.451 indivíduos (7.255 indivíduos.ha-1), tendo sido identificadas 85 espécies, 52 gêneros e 31 famílias (Tabela 1), sendo que 24 indivíduos permaneceram identificados apenas como morfo-espécies em nível de família por falta de material reprodutivo. As seguintes espécies predominaram na área, segundo os valores de importância (IVI): Myrcia língua (O. Berg) Mattos, Myrtaceae $(39,89)$; Xylopia aromatica (Lam.) Mart., Annonaceae $(24,07)$ e Anadenanthera falcata (Benth.) Speg, Leguminosae (22,20). As duas primeiras espécies apresentaram valores elevados de IVI devido principalmente a sua ocorrência em maior abundância e a terceira devido a dominância relativa (DoR) apareceu em primeiro lugar $(17,7 \%)$, seguida pela $M$. lingua $(15,4 \%)$ e $X$. aromatica $(10,2 \%)$. Segundo a altura média, A. falcata dominou o dossel (7,0 $\pm 2,8 \mathrm{~m})$, M. lingua o sub-bosque $(2,6 \pm 1,1 \mathrm{~m})$ e $X$. aromatica o estrato intermediário $(5,3 \pm 2,1 \mathrm{~m})$. 


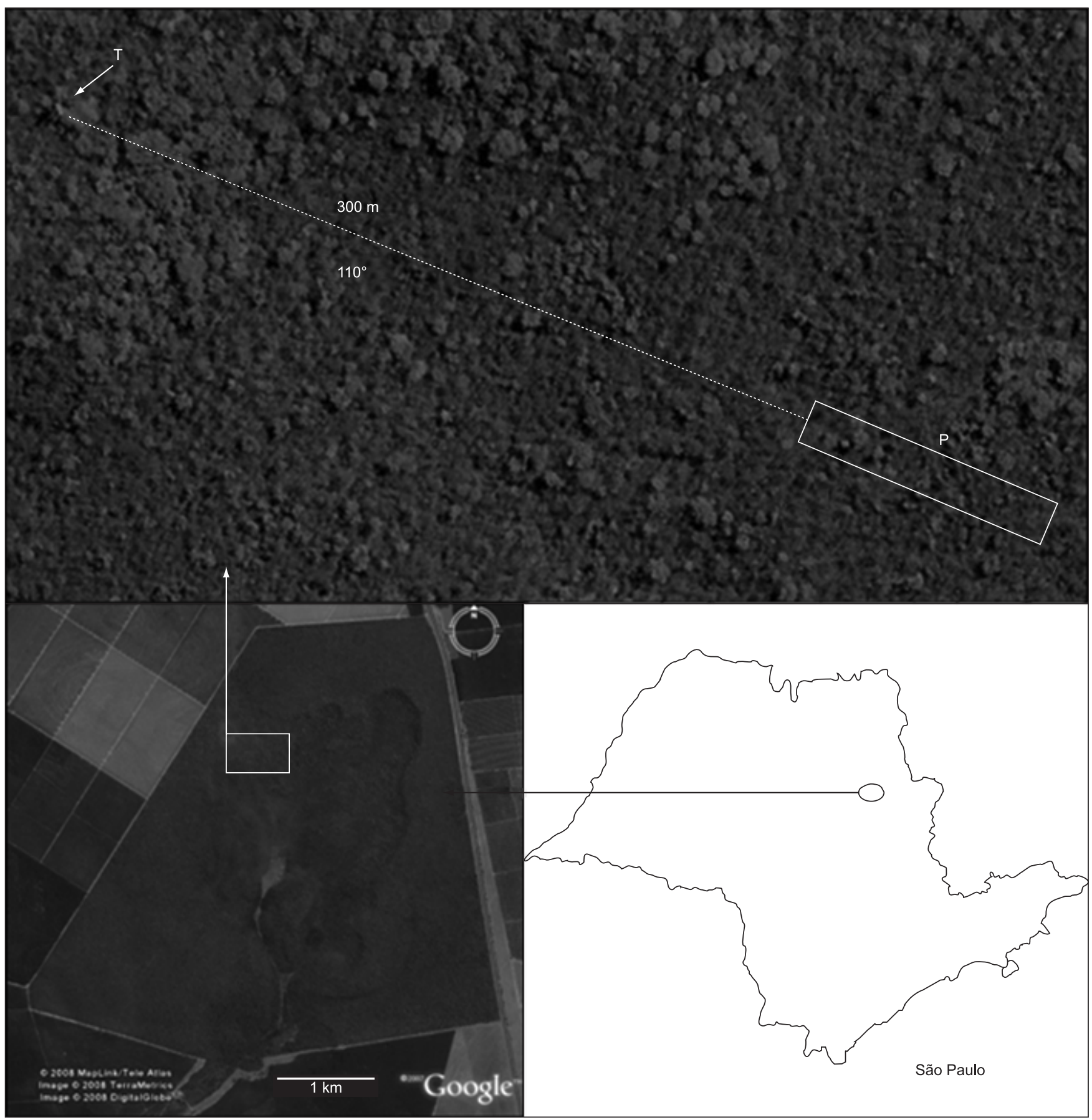

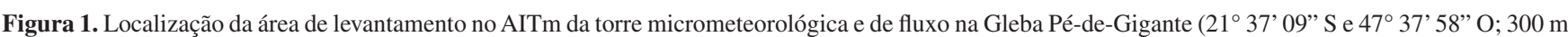
em direção $110^{\circ}$ ) no estado de São Paulo; T - Torre micrometeorológica e de fluxo de carbono (seta); (P) Área de levantamento fitossociológico (polígono).

Figure 1. Localization of the flux tower footprint in Pé-de-Gigante site $\left(21^{\circ} 37^{\prime} 09^{\prime \prime} \mathrm{S}\right.$ e $47^{\circ} 37^{\prime} 58^{\prime \prime} \mathrm{W}$, distance and direction in geographical $\left.110^{\circ}\right)$ in Sao Paulo State; T - Micrometeorological and flux tower (arrow); (P) Phytosociological inventory area (polygon).

O índice de Morisita (1954) calculado para as três espécies de maior importância alcançou os valores de 1,8 para A. falcata; 1,01 para $M$. língua; e 1,01 para X. aromatica, indicando uma distribuição agregada para a primeira espécie. As demais espécies evidenciaram distribuição homogênea na parcela. O Índice de diversidade de Shannon $\left(\mathrm{H}^{\prime}\right.$ ) foi de 3,27 nats.ind $^{-1}$ (equabilidade de $70 \%$ ) e $7,9 \mathrm{~m}^{2} . \mathrm{ha}^{-1}$ de Área basal (Tabela 2).

A distribuição de freqüência em classes de diâmetro (Figura 2) das nove primeiras espécies em importância na área indica que apenas A. falcata, Copaifera langsdorffii Desf., Platypodium elegans
Vogel e Annona coriacea Mart. apresentaram indivíduos nas maiores classes, com as duas primeiras mostrando certa homogeneidade na distribuição dos indivíduos em todas as classes de diâmetro. As espécies M. lingua, X. aromatica, Diptychandra aurantiaca Tul., Aspidosperma tomentosum Mart., Schefflera vinosa (Cham. \& Schltdl.) Frodin \& Fiaschi, Platypodium elegans e Anonna coriacea apresentaram maior distribuição de indivíduos nas três primeiras classes de diâmetro ( 5 a $15 \mathrm{~cm}$ ). Com destaque para A. tomentosa e S. vinosa, que apresentaram mais de $80 \%$ dos indivíduos na menor classe de diâmetro. 
Tabela 1. Parâmetros fitossociológicos das espécies com perímetro acima do solo $(10 \mathrm{~cm})$ igual ou maior que $6 \mathrm{~cm}$, cerrado sensu stricto, Gleba Pé-de-Gigante, Parque Estadual de Vassununga, Santa Rita do Passa Quatro, SP, em ordem decrescente de IVI. NI - Número de indivíduos; AB - Área Basal ( $\left.\mathrm{m}^{2}\right)$; FR - Freqüência Relativa (\%); DR - Densidade Relativa (\%); DoR - Dominância Relativa (\%); IVI - Índice do Valor de Importância.

Table 1. Phytosociological species parameters with perimeter above ground $(10 \mathrm{~cm})$ equal or bigger than $6 \mathrm{~cm}$, cerrado sensu stricto, Pé-de-Gigante site, Vassununga State Park, Santa Rita do Passa Quatro, SP, in decreasing order of IVI. NI - Individuals number; AB - Basal Area $\left(\mathrm{m}^{2}\right)$; FR - Relative Frequency (\%); DR - Relative Density (\%); DoR - Relative Dominance (\%); IVI - Importance value rate.

\begin{tabular}{|c|c|c|c|c|c|c|c|}
\hline Espécie & Família & NI & $\mathbf{A B}$ & FR & DR & DoR & IVI \\
\hline Myrcia lingua (O.Berb) Mattos & MYRTACEAE & 294 & 1,2182 & 4,26 & 20,26 & 15,37 & 39,89 \\
\hline Xylopia aromatica (Lam.) Mart. & ANNONACEAE & 139 & 0,8108 & 4,26 & 9,58 & 10,23 & 24,07 \\
\hline Anadenanthera falcata (Benth.) Speg. & LEGUMINOSAE - MIMOSOIDEAE & 35 & 1,3999 & 2,13 & 2,41 & 17,67 & 22,20 \\
\hline Diptychandra aurantiaca (Mart.) Tul. & LEGUMINOSAE - CAESALPINIOIDEAE & 116 & 0,6683 & 4,04 & 7,99 & 8,43 & 20,47 \\
\hline Aspidosperma tomentosum Mart. & APOCYNACEAE & 135 & 0,1756 & 4,04 & 9,30 & 2,22 & 15,56 \\
\hline Schefflera vinosa (Cham. \& Schltdl.) Frodin & ARALIACEAE & 77 & 0,0752 & 4,04 & 5,31 & 0,95 & 10,30 \\
\hline Platypodium elegans Vogel & LEGUMINOSAE - FABOIDEAE & 33 & 0,3465 & 3,62 & 2,27 & 4,37 & 10,26 \\
\hline Annona coriacea Mart. & ANNONACEAE & 46 & 0,2130 & 4,04 & 3,17 & 2,69 & 9,90 \\
\hline Copaifera langsdorffii Desf. & LEGUMINOSAE - CAESALPINIOIDEAE & 17 & 0,4650 & 2,55 & 1,17 & 5,87 & 9,59 \\
\hline Qualea multiflora Mart. & VOCHYSIACEAE & 46 & 0,1526 & 3,62 & 3,17 & 1,93 & 8,71 \\
\hline Miconia sp 2 Ruiz \& Pav. & MELASTOMATACEAE & 57 & 0,0671 & 3,19 & 3,93 & 0,85 & 7,97 \\
\hline Ficus guaratinica Schodat & MORACEAE & 18 & 0,3344 & 1,91 & 1,24 & 4,22 & 7,38 \\
\hline Miconia sp 1 Ruiz \& Pav. & MELASTOMATACEAE & 39 & 0,0600 & 3,19 & 2,69 & 0,76 & 6,64 \\
\hline Qualea parviflora Mart. & VOCHYSIACEAE & 33 & 0,2076 & 1,70 & 2,27 & 2,62 & 6,60 \\
\hline Ouratea spectabilis (Mart.) Engl. & OCHNACEAE & 26 & 0,1053 & 3,40 & 1,79 & 1,33 & 6,52 \\
\hline Dalbergia miscolobium Benth. & LEGUMINOSAE - FABOIDEAE & 21 & 0,1285 & 1,91 & 1,45 & 1,62 & 4,98 \\
\hline Myrcia cf. bella Cambess. & MYRTACEAE & 27 & 0,0430 & 2,34 & 1,86 & 0,54 & 4,74 \\
\hline Andira cf. laurifoliaBenth. & LEGUMINOSAE - FABOIDEAE & 8 & 0,2075 & 1,06 & 0,55 & 2,62 & 4,23 \\
\hline Eugenia hyemalis Cambess. & MYRTACEAE & 13 & 0,0668 & 2,13 & 0,90 & 0,84 & 3,87 \\
\hline Bauhinia rufa (Bong.) Steud. & LEGUMINOSAE - CERCIDEAE & 19 & 0,0314 & 2,13 & 1,31 & 0,40 & 3,83 \\
\hline Byrsonima coccolobifolia Kunth & MALPIGHIACEAE & 15 & 0,0540 & 1,91 & 1,03 & 0,68 & 3,63 \\
\hline Plathymenia reticulata Benth. & VOCHYSIACEAE & 8 & 0,1451 & 1,06 & 0,55 & 1,83 & 3,45 \\
\hline Machaerium acutifolium Vog. & LEGUMINOSAE - CAESALPINIOIDEAE & 15 & 0,0484 & 1,70 & 1,03 & 0,61 & 3,35 \\
\hline Miconia sp 3 Ruiz \& Pav. & MELASTOMATACEAE & 14 & 0,0185 & 2,13 & 0,96 & 0,23 & 3,33 \\
\hline Miconia stenostachya DC. & MELASTOMATACEAE & 12 & 0,0152 & 1,49 & 0,83 & 0,19 & 2,51 \\
\hline Hymenaea martiana Hayne & LEGUMINOSAE - CAESALPINIOIDEAE & 11 & 0,0620 & 0,85 & 0,76 & 0,78 & 2,39 \\
\hline Dimorphandra mollis Benth. & LEGUMINOSAE - MIMOSOIDEAE & 6 & 0,0693 & 1,06 & 0,41 & 0,87 & 2,35 \\
\hline Qualea grandiflora Mart. & VOCHYSIACEAE & 6 & 0,0784 & 0,85 & 0,41 & 0,99 & 2,25 \\
\hline Roupala montana Aubl. & PROTEACEAE & 8 & 0,0276 & 1,28 & 0,55 & 0,35 & 2,18 \\
\hline Tocoyena formosa (Cham. \& Schltdl) K.Schum & RUBIACEAE & 9 & 0,0206 & 1,28 & 0,62 & 0,26 & 2,16 \\
\hline Coussarea cf. hydrangeaefolia (Benth.) Müll. & RUBIACEAE & 2 & 0,1246 & 0,43 & 0,14 & 1,57 & 2,14 \\
\hline Miconia chamissois Naudin & MELASTOMATACEAE & 7 & 0,0096 & 1,49 & 0,48 & 0,12 & 2,09 \\
\hline Campomanesia pubescens Cambess. & MYRTACEAE & 12 & 0,0365 & 0,43 & 0,83 & 0,46 & 1,71 \\
\hline Miconia rubiginosa (Bonpl.) Cogn. & MELASTOMATACEAE & 5 & 0,0091 & 1,06 & 0,34 & 0,12 & 1,52 \\
\hline Virola sebifera Aubl. & MYRISTICACEAE & 5 & 0,0156 & 0,85 & 0,34 & 0,20 & 1,39 \\
\hline Ocotea pulchella Mart. & LAURACEAE & 1 & 0,0875 & 0,21 & 0,07 & 1,10 & 1,39 \\
\hline Licania humilis Cham. \& Schlecht. & CHRYSOBALANACEAE & 5 & 0,0137 & 0,85 & 0,34 & 0,17 & 1,37 \\
\hline Eugenia aurata O.Berg & MYRTACEAE & 6 & 0,0243 & 0,64 & 0,41 & 0,31 & 1,36 \\
\hline Eugenia bimarginata DC. & MYRTACEAE & 4 & 0,0089 & 0,85 & 0,28 & 0,11 & 1,24 \\
\hline Duguetia furfuraceae (A.St.-Hil.) Saff. & ANNONACEAE & 4 & 0,0035 & 0,85 & 0,28 & 0,04 & 1,17 \\
\hline Diospyros inconstans Jacq. & EBENACEAE & 2 & 0,0383 & 0,43 & 0,14 & 0,48 & 1,05 \\
\hline Ocotea corymbosa (Meisn.) Mez & LAURACEAE & 2 & 0,0378 & 0,43 & 0,14 & 0,48 & 1,04 \\
\hline Guapira graciliflora (.Schmidt) Lundell & NYCTAGINACEAE & 4 & 0,0088 & 0,64 & 0,28 & 0,11 & 1,03 \\
\hline Pseudobombax grandiflorum (Cav.) A.Robyns & MALVACEAE & 3 & 0,0056 & 0,64 & 0,21 & 0,07 & 0,92 \\
\hline Cybistax antisyphilitica (Mart.) Mart. & BIGNONIACEAE & 3 & 0,0039 & 0,64 & 0,21 & 0,05 & 0,89 \\
\hline Casearia gossypiosperma Briq. & SALICACEAE & 4 & 0,0036 & 0,43 & 0,28 & 0,05 & 0,75 \\
\hline
\end{tabular}


Tabela 1. Continuação.

\begin{tabular}{|c|c|c|c|c|c|c|c|}
\hline Espécie & Família & NI & $\mathbf{A B}$ & FR & DR & DoR & IVI \\
\hline Alibertia concolor (Cham.) K. Schum. & RUBIACEAE & 2 & 0,0069 & 0,43 & 0,14 & 0,09 & 0,65 \\
\hline Miconia albicans (Sw.) Triana & MELASTOMATACEAE & 2 & 0,0066 & 0,43 & 0,14 & 0,08 & 0,65 \\
\hline Piptocarpha rotundifolia (Less.) Baker & ASTERACEAE & 2 & 0,0058 & 0,43 & 0,14 & 0,07 & 0,64 \\
\hline Hymenaea stigonocarpa Mart. ex Hayne & LEGUMINOSAE - CAESALPINIOIDEAE & 2 & 0,0058 & 0,43 & 0,14 & 0,07 & 0,64 \\
\hline Pseudobombax longiflorum (Mart.\& Zucc.) A.Robyns & MALVACEAE & 2 & 0,0047 & 0,43 & 0,14 & 0,06 & 0,62 \\
\hline Miconia cinnamomifolia (DC.) Naud. & MELASTOMATACEAE & 2 & 0,0041 & 0,43 & 0,14 & 0,05 & 0,62 \\
\hline Palicourea rigida Kunth & RUBIACEAE & 2 & 0,0026 & 0,43 & 0,14 & 0,03 & 0,60 \\
\hline Eugenia punicifolia (Kunth.) DC. & MYRTACEAE & 2 & 0,0024 & 0,43 & 0,14 & 0,03 & 0,59 \\
\hline Tabebuia ochracea (Cham.) Standl. & BIGNONIACEAE & 2 & 0,0023 & 0,43 & 0,14 & 0,03 & 0,59 \\
\hline Myrcia albotomentosa DC & MYRTACEAE & 2 & 0,0019 & 0,43 & 0,14 & 0,02 & 0,59 \\
\hline Tabebuia $\mathrm{sp}$ & BIGNONIACEAE & 2 & 0,0017 & 0,43 & 0,14 & 0,02 & 0,59 \\
\hline Miconia fallax DC. & MELASTOMATACEAE & 2 & 0,0012 & 0,43 & 0,14 & 0,01 & 0,58 \\
\hline Plenckia populnea Reissek & CELASTRACEAE & 2 & 0,0008 & 0,43 & 0,14 & 0,01 & 0,57 \\
\hline Alibertia sessilis (Vell.) K.Schum. & RUBIACEAE & 2 & 0,0006 & 0,43 & 0,14 & 0,01 & 0,57 \\
\hline Vatairea macrocarpa (Benth.) Ducke & LEGUMINOSAE - FABOIDEAE & 1 & 0,0215 & 0,21 & 0,07 & 0,27 & 0,55 \\
\hline Caryocar brasiliense Cambess. & CARYOCARACEAE & 1 & 0,0176 & 0,21 & 0,07 & 0,22 & 0,50 \\
\hline Lafoensia pacari St. Hil & LYTHRACEAE & 1 & 0,0161 & 0,21 & 0,07 & 0,20 & 0,48 \\
\hline Vochysia cinnamomea Pohl & VOCHYSIACEAE & 1 & 0,0097 & 0,21 & 0,07 & 0,12 & 0,40 \\
\hline Kielmeyera variabilis Mart. & CLUSIACEAE & 1 & 0,0087 & 0,21 & 0,07 & 0,11 & 0,39 \\
\hline Casearia decandra Jacq. & FLACOURTINACEAE & 2 & 0,0021 & 0,21 & 0,14 & 0,03 & 0,38 \\
\hline Byrsonima sp & MALPIGHIACEAE & 2 & 0,0009 & 0,21 & 0,14 & 0,01 & 0,36 \\
\hline Acosmium dasycarpum (Vog.) Yakovl. & LEGUMINOSAE - FABOIDEAE & 1 & 0,0050 & 0,21 & 0,07 & 0,06 & 0,34 \\
\hline Terminalia argentea Mart. et Zucc. & COMBRETACEAE & 1 & 0,0035 & 0,21 & 0,07 & 0,04 & 0,33 \\
\hline Strychnos pseudoquina A.St.-Hil. & LOGANIACEAE & 1 & 0,0029 & 0,21 & 0,07 & 0,04 & 0,32 \\
\hline Tabebuia aurea (Manso) Benth. \& Hook. & BIGNONIACEAE & 1 & 0,0023 & 0,21 & 0,07 & 0,03 & 0,31 \\
\hline Campomanesia pubescens (DC.) Berg. & MYRTACEAE & 1 & 0,0016 & 0,21 & 0,07 & 0,02 & 0,30 \\
\hline Miconia albotomentosa DC & MYRTACEAE & 1 & 0,0010 & 0,21 & 0,07 & 0,01 & 0,29 \\
\hline Alibertia macrophylla K. Schum. & RUBIACEAE & 1 & 0,0010 & 0,21 & 0,07 & 0,01 & 0,29 \\
\hline Diospyros hyspida A.DC. & EBENACEAE & 1 & 0,0009 & 0,21 & 0,07 & 0,01 & 0,29 \\
\hline Alibertia $\mathrm{sp}$ & RUBIACEAE & 1 & 0,0006 & 0,21 & 0,07 & 0,01 & 0,29 \\
\hline Annona crassiflora Mart. & ANNONACEAE & 1 & 0,0006 & 0,21 & 0,07 & 0,01 & 0,29 \\
\hline Miconia fallax DC & MELASTOMATACEAE & 1 & 0,0006 & 0,21 & 0,07 & 0,01 & 0,29 \\
\hline Pseudobombax grandiflorum (Cav.) A.Robyns & BOMBACACEAE & 1 & 0,0004 & 0,21 & 0,07 & 0,01 & 0,29 \\
\hline Tapirira guianensis Aubl. & ANACARDIACEAE & 1 & 0,0004 & 0,21 & 0,07 & 0,00 & 0,29 \\
\hline Qualea sp & VOCHYSIACEAE & 1 & 0,0004 & 0,21 & 0,07 & 0,00 & 0,29 \\
\hline Byrsonima laxiflora Griseb. & MALPIGHIACEAE & 1 & 0,0003 & 0,21 & 0,07 & 0,00 & 0,29 \\
\hline Aspidosperma polyneuron Müll. Arg. & APOCYNACEAE & 1 & 0,0003 & 0,21 & 0,07 & 0,00 & 0,29 \\
\hline Eugenia punicifolia (H.B.K.) DC & MYRTACEAE & 1 & 0,0003 & 0,21 & 0,07 & 0,00 & 0,29 \\
\hline Eugenia brasiliensis Lam. & MYRTACEAE & 1 & 0,0003 & 0,21 & 0,07 & 0,00 & 0,29 \\
\hline não identificadas & & 24 & 0,0310 & 4,69 & 1,61 & 0,44 & 6,70 \\
\hline
\end{tabular}

Tabela 2. Comparação entre variáveis estruturais (densidade e área basal total) em diferentes áreas de Cerrado no Brasil.

Table 2. Comparison between structural parameters (density and total basal area) in different areas of Brazilian Cerrado.

\begin{tabular}{lccl}
\hline \multicolumn{1}{c}{ Local de Estudo } & Densidade ind.ha $^{\mathbf{- 1}}$ & ${\text { Área Basal } \mathbf{~ m}^{\mathbf{2}} \text {.ha }^{\mathbf{1}}}^{\text {Referência }}$ \\
\hline Chapadaa Pratinha (MG) e dos Veadeiros (GO) & 1130 & 5,8 a 11,3 & Felfili et al. (1997) \\
Água Boa (MT) & 995 & 7,5 & Felfili et al. (2002) \\
RECOR-IBGE (Brasília) & 1964 & 13,3 & Andrade et al. (2002) \\
Brotas (SP) & 1150 & 7,2 & Duringan et al. (2002) \\
Sul Pé-de-Gigante (SP) & 13976 & 4,9 & Fidelis \& Godoy (2003) \\
APA (Brasília) & 882 & 9,5 & Assunção \& Felfili (2004) \\
AITm Pé-de-Gigante & 7255 & 7,9 & este estudo \\
\hline
\end{tabular}



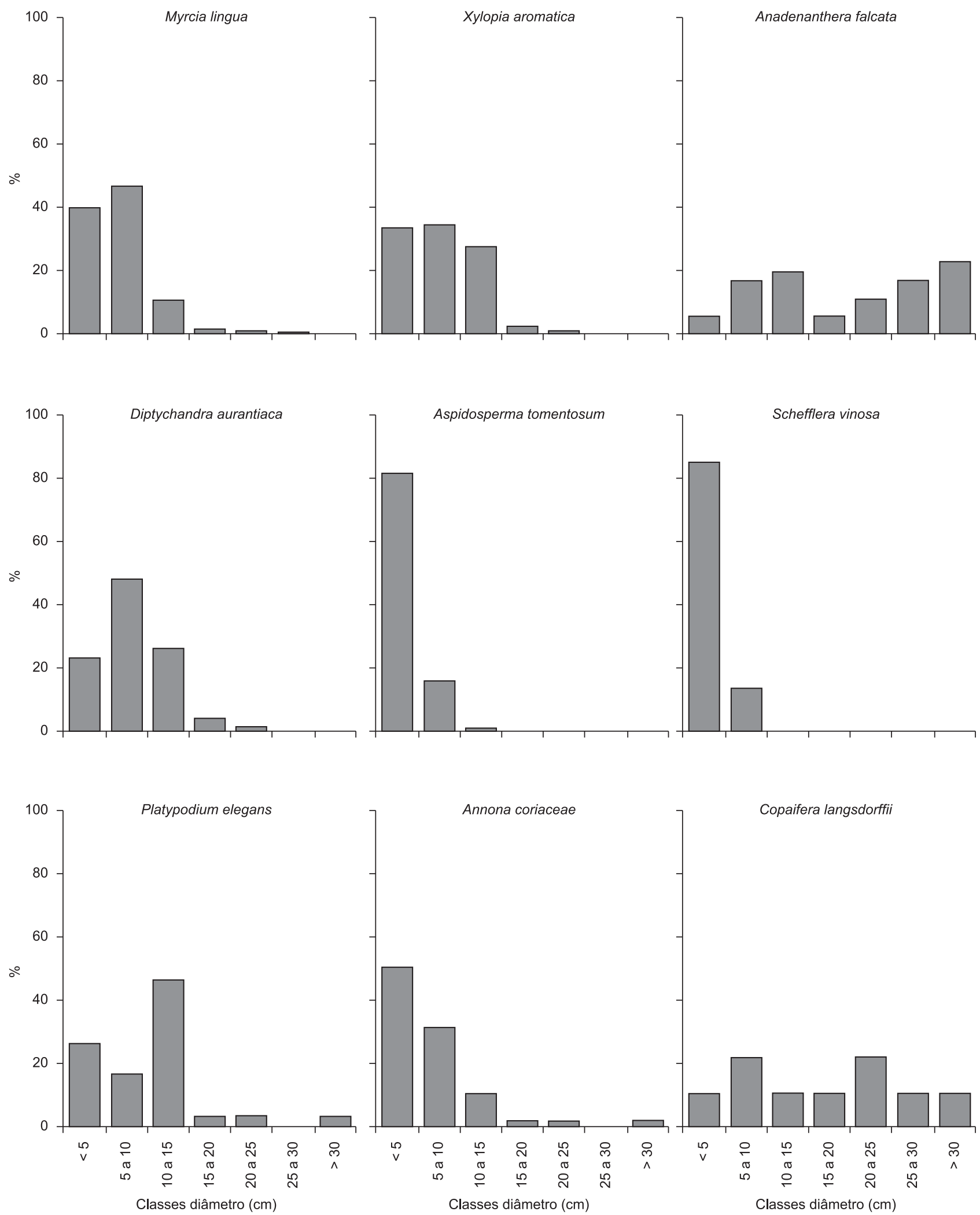

Figura 2. Distribuição de freqüência em classes de diâmetro das espécies levantadas no cerrado sensu stricto na AITm da torre micrometeorológica e de fluxo, Gleba Pé-de-Gigante, Parque Estadual de Vassununga.

Figure 2. Diameter class frequency distribution of the studied species in cerrado sensu stricto in the micrometeorological tower footprint, Pé-de-Gigante site, Vassununga State Park. 
Latansio-Aidar, S.R. et al.
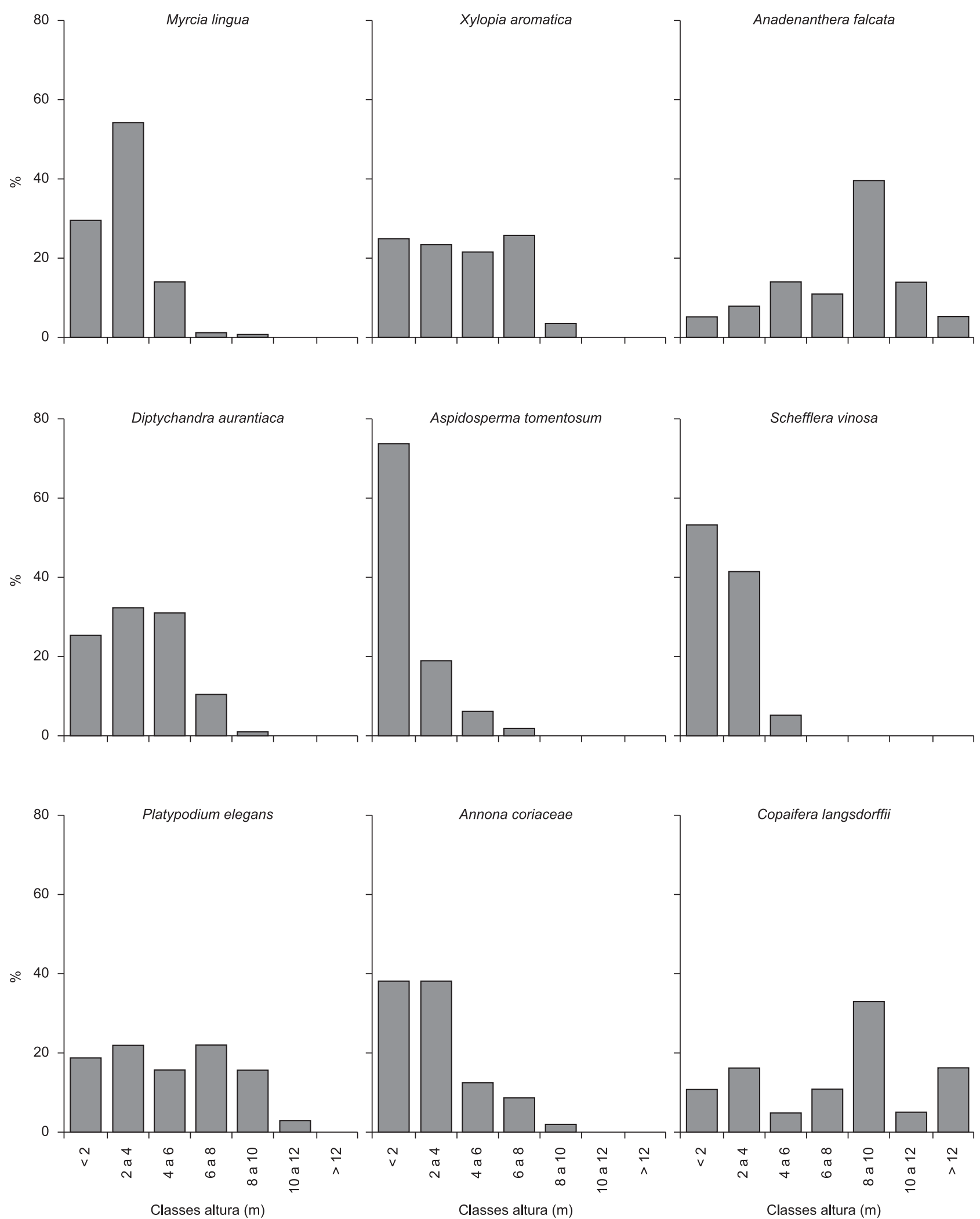

Figura 3. Distribuição de freqüência em classes de altura (m) das espécies levantadas no cerrado sensu stricto na AITm da torre micrometeorológica e de fluxo, Gleba Pé-de-Gigante, Parque Estadual de Vassununga.

Figure 3. Height class frequency distribution (m) of species in cerrado sensu stricto in the micrometeorological tower footprint, Pé-de-Gigante site, Vassununga State Park. 
Tabela 3. Número de espécies (spp), número de indivíduos (ni), Dominância relativa (DoR) e índice de valor de importância (IVI) das principais famílias presentes no AITm da torre de fluxo, cerrado sensu stricto, Gleba Pé-deGigante, Parque Estadual de Vassununga.

Table 3. Species number (spp), individuals number (ni), Relative dominance (DoR) and importance value rate (IVI) of main families present in footprint tower flux, cerrado sensu stricto, Pé-de-Gigante site, Vassununga State Park.

\begin{tabular}{llrrc}
\hline \multicolumn{1}{c}{ Família } & spp & ni & DoR & IVI \\
\hline LEGUMINOSAE & 13 & 285 & 43,6 & 85,2 \\
$\quad$ (CAESALPINIOIDEAE) & $(6)$ & $(161)$ & $(15,8)$ & $(36,47)$ \\
$\quad$ (FABOIDEAE) & $(5)$ & $(64)$ & $(8,9)$ & $(15,4)$ \\
$\quad$ (MIMOSOIDEAE) & $(2)$ & $(41)$ & $(18,5)$ & $(24,6)$ \\
$\quad$ (CERCIDEAE) & $(1)$ & $(19)$ & $(0,4)$ & $(3,83)$ \\
MYRTACEAE & 12 & 364 & 17,7 & 55,5 \\
MELASTOMATACEAE & 10 & 141 & 2,4 & 26,2 \\
RUBIACEAE & 7 & 19 & 2,0 & 6,7 \\
VICHYSIACEAE & 6 & 95 & 7,5 & 21,7 \\
ANNONACEAE & 4 & 190 & 13,0 & 35,4 \\
BIGNONIACEAE & 4 & 8 & 0,1 & 2,4 \\
\hline
\end{tabular}

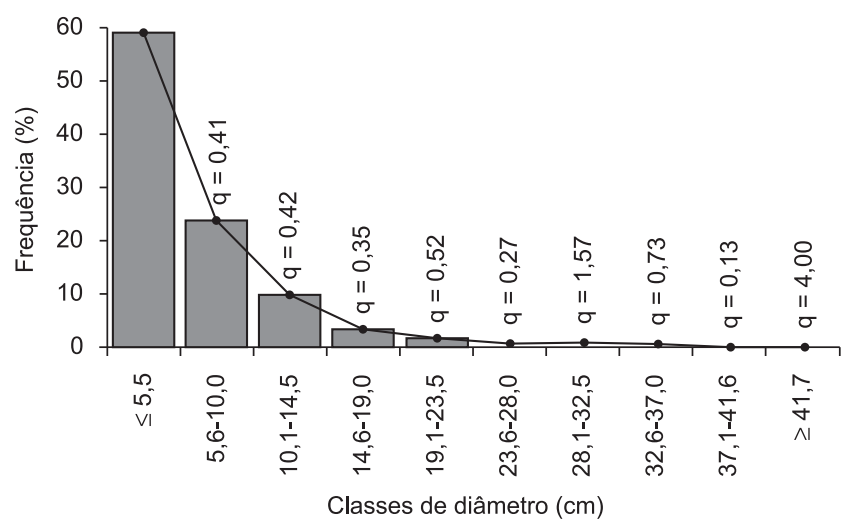

Figura 4. Distribuição de frequiência em classes de diâmetro $(\mathrm{cm})$ para a comunidade amostrada na AITm da torre micrometeorológica e de fluxo no cerrado sensu stricto, Gleba Pé-de-Gigante, Parque Estadual de Vassununga. Classes fixas de $4,5 \mathrm{~cm}$. 1) 1 a 5,5 ; 2) 5,6 a 10; 3) 10,1 a 14,5 ... 10) 41,7 a 46 .

Figure 4. Diameter classes frequency distribution $(\mathrm{cm})$ for sampled community in the footprint of micrometeorological tower in cerrado sensu stricto, Pé-de-Gigante site, Vassununga State Park. Fixed classes 4,5cm. 1) 1 a 5,5; 2) 5,6 a 10 ; 3$) 10,1$ a $14,5 \ldots$ 10) 41,7 a 46.

Em relação à distribuição em classes de altura (Figura 3), as espécies mostraram padrões similares à distribuição de diâmetros, A. falcata e C. langsdorffi com maioria de indivíduos entre 8 e $10 \mathrm{~m}$ de altura, $X$. aromatica, $D$. aurantiaca e $P$. elegans com maioria de indivíduos entre 2 e $8 \mathrm{~m}$ e $M$. lingua, A. tomentosum, $S$. vinosa e A. coriacea com maioria de indivíduos menores que $4 \mathrm{~m}$. Apenas A. falcata e C. langsdorffii possuíram indivíduos em todas as classes de altura. A. tomentosum e $S$. vinosa apresentaram mais que $50 \%$ de seus indivíduos com menos de $2 \mathrm{~m}$.

A família Leguminosae apresentou o maior número de espécies (13) e maior IVI $(85,2)$. E em relação ao número de espécies dentro de cada família vêm a seguir as famílias Myrtaceae (12), Melastomataceae (10), Rubiaceae (7), Vochysiaceae (6), Annonaceae (4) e Bignoniaceae (4) (Tabela 3). Em relação ao número de indivíduos, as famílias mais importantes foram: Myrtaceae (364), Leguminosae (285) e Annonaceae (190).

A estrutura da vegetação, analisada por meio da distribuição de diâmetro dos indivíduos presentes na área apresenta distribuição de "J" invertido (Figura 4) com predominância de indivíduos na classe inicial $(58,8 \%)$.

\section{Discussão}

A presença da espécie $A$. falcata como espécie de maior importância (maior IVI) na área deste estudo é incomum nos Cerrados centrais do Brasil e quando ocorre nos Cerrados paulistas não é tão freqüente, se mantendo sempre no final da lista do IVI. Além do presente estudo, essa alta importância da espécie foi apenas verificada em uma área de Cerrado do município de São Carlos (Oliveira \& Batalha 2005). A espécie $M$. lingua foi relatada no Cerrado de Assis (Brando \& Durigan 2004), em Cerrado (Durigan et al. 2002) e cerradão (Gomes et al. 2004) em Brotas, mas sem muita importância na lista de espécies. Já a espécie $X$. aromatica é bastante comum nos Cerrados paulistas, porém só foi relatada com alto IVI no Cerrado Pé-de-Gigante (Fidelis \& Godoy 2003) e em um cerradão de Brotas (Gomes et al. 2004). As espécies S. vinosa, P. elegans, A. coriacea, C. langsdorffii ocorrem com frequência em Cerrados paulistas, mas com IVI relativamente baixos (menores que 6) (Durigan et al. 2003, Brando \& Durigan 2004, Gomes et al. 2004, Oliveira \& Batalha 2005). Já as espécies $D$. aurantiaca e $A$. tomentosum, não são comuns na maioria dos Cerrados paulistas (Durigan et al. 2003).

No trabalho de Castro (1987), realizado em área sudeste do Péde-Gigante, a espécie $M$. lingua mostrou maior importância (IVI 27,41), seguida de D. aurantiaca (IVI 19,77), A. falcata (IVI 18,29) e $X$. aromatica (IVI 14,91), enquanto que no levantamento realizado por Fidelis \& Godoy (2003) em área sul do Cerrado Pé-de-Gigante A. falcata mostrou IVI de 40,28 e X. aromatica obteve 12,05 de IVI. Ambos os estudos mantiveram semelhança estrutural com a área levantada nesse estudo (A. falcata IVI 22,20, X. aromatica IVI 24,07 e M. lingua IVI 39.89) já que são áreas do mesmo fragmento de Cerrado. Porém no levantamento realizado pelo presente estudo observamos maior importância das espécies $M$. lingua e $X$. aromatica que nos demais levantamentos, a espécie $A$. falcata se mostrou mais importante na área de borda levantada por Fidelis \& Godoy (2003), o que concorda com seu hábito heliófilo (Carvalho 2003). Por outro lado, a presença em maior importância da espécie sempre verde M. lingua, sugerindo ocorrência de adensamento da vegetação, que permitiu maior sombreamento e com isso possível favorecimento da ocorrência dessa espécie.

A distribuição agregada para A. falcata, evidenciada pelo índice de Morisita, sugere alta capacidade de reprodução vegetativa (ou rebrota) (Vieira et al. 2006) ao contrário da distribuição homogênea encontrada para $M$. lingua e $X$. aromatica. Esse padrão pode ser mais bem observado na análise dos indivíduos de acordo com as distâncias de x e y, medidas durante a fitossociologia (dados não mostrados). Ocorreu um claro agrupamento de A. falcata em metade da área amostrada ( $0,1 \mathrm{ha})$ enquanto que as demais espécies se distribuem em todas as 20 sub-parcelas da unidade amostral (0,2 ha).

A. falcata, com indivíduos em todas as classes de altura e diâmetro e terceira espécie em importância, mostrou-se a espécie que melhor define o dossel da área de estudo, sendo caracterizada como uma espécie decídua (Lorenzi 1998). X. aromatica, com indivíduos dominando o estrato intermediária e segunda em importância, mostrou-se a espécie mais característica do sub-dossel, e é caracterizada como espécie brevidecídua. A espécie $M$. lingua, mostrou-se a mais representativa do sub-bosque e de maior importância na área de estudo e caracteriza-se por hábito sempre-verde. Assim, estas três espécies de 
maior importância na área, ocupam diferentes estratos na formação vegetal, apresentam também diferentes estratégias fenológicas, e caracterizam a fisionomia do Cerrado presente na área de estudo, semelhante ao encontrado por castro (1987), porém aqui observamos maior altura nos indivíduos de A. falcata.

A estrutura da vegetação na área estudada, com distribuição de "J" invertido e predominância da classe inicial $(58,8 \%)$, é similar à encontrada por Fidelis \& Godoy (2003) em área de borda sul do Pé-de-Gigante. Entretanto, a análise sugeriu que a comunidade deste estudo estava em condição mais avançada de desenvolvimento, ao contrário do indicado no estudo de Fidelis \& Godoy (2003). Esse aspecto é reforçado quando analisamos o valor máximo de diâmetro $(57 \mathrm{~cm})$, maior que os encontrados ao sul do Pé-de-Gigante por Fidelis \& Godoy $(25,5 \mathrm{~cm})$. Ainda, as razões "q" encontradas não apresentaram valor constante, como os encontrados por estes autores, evidenciando condições não balanceadas, típicas de formações florestais (Harper 1977).

O valor de área basal de 7,9 $\mathrm{m}^{2}$.ha ${ }^{-1}$ é similar aos encontrados por outros autores e o de densidade é expressivamente mais alto quando comparado a Cerrados da região central do Brasil (Tabela 2). Considerando os Cerrados de Brasília (APA e RECOR-IBGE) (Andrade et al. 2002, Assunção \& Felfili 2004), e da Chapada dos Veadeiros (Felfili et al. 1997), estes apresentaram maior área basal que a do presente estudo e com muito menor densidade de indivíduos, mostrando que a densidade foi o fator fundamental na determinação dos valores de área basal encontrado no AIT, Pé-de-Gigante.

Comparando com os valores encontrados por Fidelis \& Godoy (2003) no mesmo Cerrado do estudo (Pé-de-Gigante), porém numa área próxima à borda sul da gleba, observamos menor densidade e maior área basal na área de estudo. Durigan et al. (2002) encontraram menor densidade e área basal em um Cerrado de Brotas. Os altos valores de área basal encontrados no presente estudo indicam a ocorrência de um adensamento da vegetação no Cerrado em questão, provavelmente devido à ausência de eventos de fogo nos últimos 40 anos, que permitiu maior densidade de indivíduos.

O Índice de diversidade de Shannon (H') (3,27 nats.ind $\left.{ }^{-1}\right)$ foi maior que os valores encontrados em Itirapina/SP $\left(\mathrm{H}^{\prime}=3,08\right)$ por Durigan et al. (2004) e em Brotas/SP $\left(H^{\prime}=3,02\right)$ por Durigan et al. (2002), com isso temos que esse Cerrado tem alta diversidade se comparado a outros Cerrados do estado de São Paulo. O índice foi, contudo, menor que aquele encontrado por Fidelis \& Godoy (2003) ao sul da área do Cerrado Pé-de-Gigante ( $\left.H^{\prime}=3,62\right)$, evidenciando o efeito de borda naquela área resultando em maior diversidade, porém com menor área basal que a área do presente estudo, que está mais centralizada no fragmento.

Os Cerrados da região central do Brasil apresentam valores de diversidade maiores que os encontrados neste estudo: 3,53 em Brasília (Andrade et al. 2002); 3,41 na APA do Paranoá, DF (Assunção \& Felfili 2004); 3,69 em Água Boa - MT (Felfili et al. 2002). Provavelmente porque os Cerrados paulistas são bastante peculiares por estarem sujeitos a geadas, muitas vezes severas, e apesar da duração do período seco ser menor do que nos Cerrados do Planalto Central, os Cerrados do limite sul enfrentam o estresse da seca somado ao das geadas e frio (Durigan et al. 2004). Além disso, penas 35\% das espécies lenhosas de todo o Cerrado ocorrem no estado de São Paulo (Ratter et al. 2003), sustentando os valores de diversidade mais baixos encontrados para os Cerrados paulistas.

As famílias de maior importância coincidem com as já citadas em literatura para a maioria dos Cerrados de maneira geral: Leguminosae, Myrtaceae, Melastomataceae, Rubiaceae, Vochysiaceae, Annonaceae e Bignoniaceae (Durigan et al. 2003, Ratter et al. 2003). A importância da família Leguminosae na composição e estrutura dos Cerrados brasileiros é amplamente reconhecida como indicado por Fidelis \& Godoy (2003). A família Myrtaceae apresentou o segundo valor de DoR associado ao grande número de indivíduos da espécie $M$. lingua.

O balanço de carbono observado na área de estudo nos anos de 2001 e 2002 (Rocha et al. 2002) indicou que o Cerrado comportouse como fonte (emissão) de carbono na época seca, tendo a deciduidade sazonal, descrita para o Cerrado Pé-de-Gigante (Batalha \& Mantovani 2005), provavelmente contribuído significativamente para a emissão observada, cabe ressaltar que as 13 espécies de leguminosas presentes na área de estudo são decíduas (Lorenzi 1998) e que somadas, contribuem com quase $30 \%$ do IVI e mais de $43 \%$ da DoR. Estes aspectos sugerem que boa parte do balanço de carbono na área está relacionando com a dinâmica fenológica das espécies de leguminosas, caracterizadas como decíduas em sua maioria, pois a deciduidade diminui o índice de área foliar, e com isso também a fotossíntese. Alterando, desse modo, o equilíbrio assimilação/ respiração e aumentando a emissão no balanço total de carbono do ecossistema (Schymanski et al. 2007).

Considerando a densidade de árvores encontrada na área e o alto valor de área basal, propomos a formação vegetal do AITm como sendo um Cerrado denso com predomínio de $M$. lingua, $X$. aromatica e A. falcata, tendo sido identificadas vegetações semelhantes apenas em áreas de transição Cerrado-cerradão ou sobre solos relativamente mais ricos, por exemplo, em áreas nas Cuestas Basálticas (Figura 5), onde o solo sofre influência das intrusões basálticas, resultando em maior fertilidade (Durigan et al. 2004). Estes autores observaram Cerrado denso em Campos Novos Paulista, Assis, Rancharia, Ribeirão Bonito, Bauru e Mojiguaçu, e ressaltam que essa formação ocorre em pequenas áreas, sendo muito rara em grandes extensões. Segundo Ribeiro \& Walter (1998) o Cerrado denso caracteriza-se por possuir uma vegetação mais aberta que o cerradão, com dossel descontínuo, quase sem gramíneas e com alta densidade de árvores e arbustos, como o observado na área de estudo.

É possível que o adensamento da vegetação seja conseqüência da ausência de fogo na região, devido principalmente à sua proteção a partir de 1970 quando foi estabelecido o parque estadual, como sugerido por autores em outras áreas de Cerrado (Moreira 2000, Henriques 2005). Cabe ressaltar ainda que além da identificação de solos relativamente mais ricos, A. falcata é uma espécie que realiza associação simbiótica com bactérias fixadoras de nitrogênio (Gross et al. 2002) podendo contribuir para o sucesso da espécie na área de estudo.

A Gleba Pé-de-Gigante é composta por um conjunto de fisionomias que compõem o contínuo proposto por Coutinho (1978), incluindo campo sujo, campo Cerrado, Cerrado sensu stricto e cerradão. Segundo Batalha et al. (2001) ocorre ainda na área floresta estacional semidecidual. O mapa de classificação da vegetação da área sugere que o AITm e a área de Fidelis \& Godoy (2003) podem ser identificadas como Cerrado sensu stricto, apesar da diferenciação estrutural entre elas. A área ao sul apresenta vegetação com menor altura (7 m) e maior densidade de indivíduos, com clara dominância de A. falcata. No AITm a maior altura (8-9 m) e menor densidade de A. falcata são evidentes. Pinheiro (2008), comparando estruturalmente Cerrado sensu stricto, cerradão, campo Cerrado e Cerrado denso em Assis, também encontrou alta densidade de A. falcata no Cerrado denso, assim como maior área basal.

Concluímos que a área de estudo pode ser classificada como Cerrado denso em adição a Cerrado sensu stricto. Além disso, apesar do tempo decorrido entre a realização dos quatro levantamentos florísticos/fitossociológicos realizados no Cerrado Pé-de-Gigante (Castro 1987, Batalha \& Mantovani 2000, Weiser \& Godoy 2003, Fidelis \& Godoy 2003) e o presente trabalho, as fisionomias sugerem 

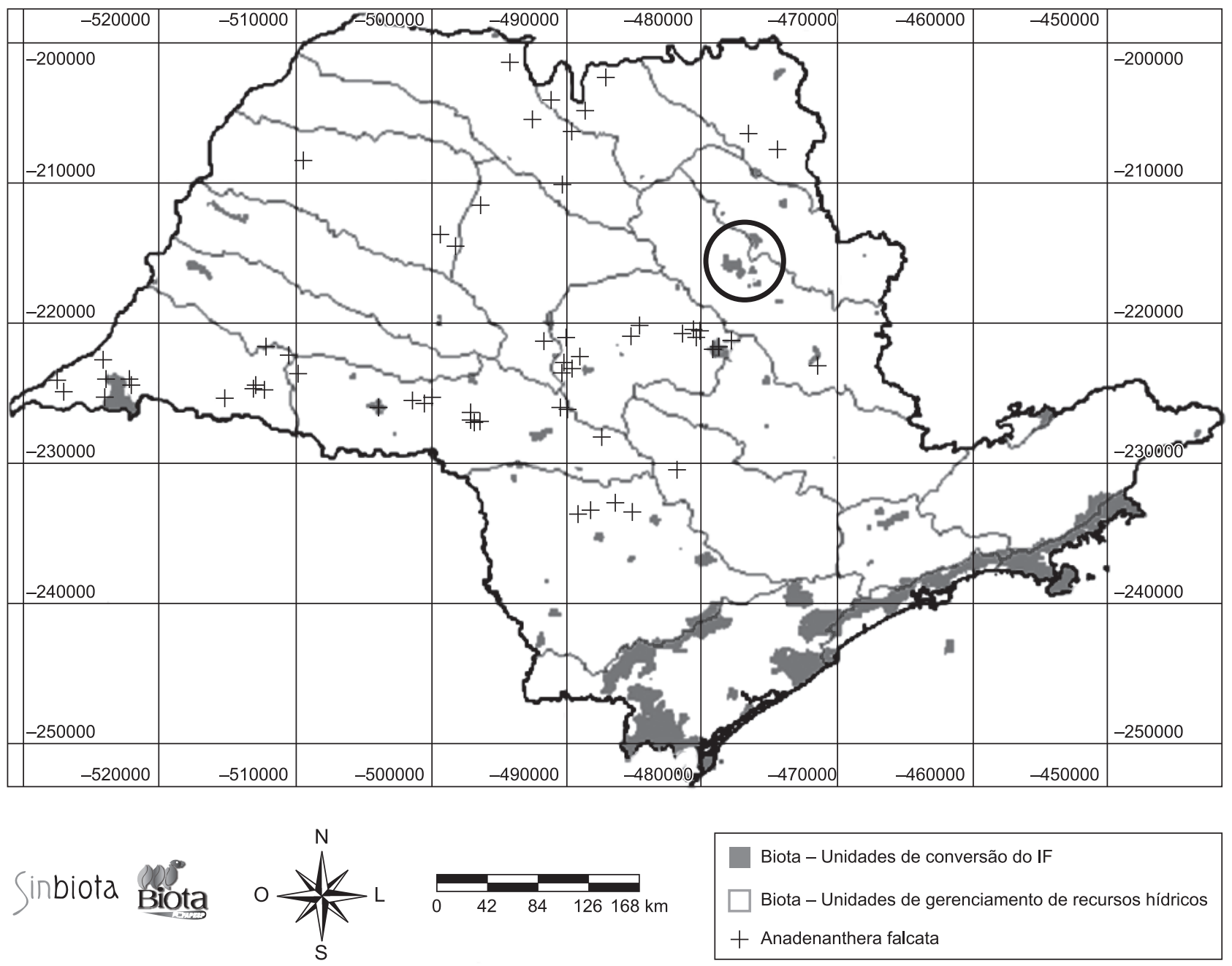

Biota - Unidades de conversão do IF

Biota - Unidades de gerenciamento de recursos hídricos

+ Anadenanthera falcata

Figura 5. Distribuição de Anadenathera falcata no estado de São Paulo, como registrado no banco de dados do Programa Biota Fapesp, Sinbiota. Círculo em vermelho indica a localização do Parque Estadual de Vassununga, que inclui a Gleba Pé-de-Gigante, onde ainda não há registro de coleta da espécie (maio 2008, http://sinbiota.cria.org.br/atlas/).

Figure 5. Anadenathera falcata distribution in São Paulo State, as registered in Biota Fapesp Program Data Bank, Sinbiota. The red circle indicates the location of Vassununga State Park, including the Pé-de-Gigante site, where there was no record of the species yet (May 2008, http://sinbiota.cria.org.br/atlas/).

uma continuidade estrutural entre essas comunidades, por meio das populações de A. falcata, espécie mais importante em todas as subáreas levantadas nesse mesmo fragmento de Cerrado ao longo dos anos. Esta diferenciação estrutural ressalta a importância do levantamento fitossociológico do AITm da torre micrometeorológica e de fluxo para um melhor entendimento da contribuição potencial da comunidade no balanço líquido de carbono avaliado localmente, permitindo, com estes resultados, a integração de escalas.

\section{Agradecimentos}

Agradecemos a Waldonésio Borges Nascimento, Antônio Crema e Dariusz Kurzatkowski, pelo apoio no levantamento fitossociológico e aos demais funcionários do Parque Estadual de Vassununga/IF, em particular ao seu diretor, Eng. Florestal Heverton José Ribeiro pela colaboração e apoio no desenvolvimento do projeto. Aos especialistas Dr. Ricardo Ribeiro Rodrigues e Dr. Vinicius Castro Souza, pelo auxílio na identificação das espécies. À FAPESP pela bolsa de mestrado concedida à primeira autora e ao Programa BIOTA/FAPESP pelo apoio financeiro.

\section{Referências}

ANDRADE, L.A.Z., FELFILI, J.M. \& VIOLATTI, L. 2002. Fitossociologia de uma área de Cerrado denso na RECOR - IBGE, Brasília - DF. Acta Bot. Bras. 16(2):225- 240.

ASSUNÇÃO, S.L. \& FELFILI, J.M. 2004. Fitossociologia de um fragmento de Cerrado sensu stricto na APA do Paranoá, DF, Brasil. Acta Bot. Bras. 18(4):903-909.

BATALHA, M.A. \& MANTOVANI, W. 2000. Reproductive phenological patterns of Cerrado plant species at the Pé-de-Gigante reserve (Santa Rita do Passa Quatro, SP, Brasil): a comparison between the herbaceous and woody flora. Rev. Bras. Biol. 60(1):129 -145.

BATALHA, M.A., MANTOVANI, W., MESQUITA JÚNIOR, H.N. 2001. Vegetation structure in Cerrado physionomies in south-eastern Brazil. Brasil. J. Biol. 61(3):475-483.

BATALHA, M.A. \& MANTOVANI, W. 2005. Alguns aspectos das comunidades vegetais. In O Cerrado do Pé-de-Gigante, Parque Estadual de Vassununga: ecologia e Conservação (V.R. Pivello \& E.M. Varanda, eds.). SMA, São Paulo.

BORGONOVI, M. \& CHIARINI, J.V. 1965. Cobertura vegetal do Estado de São Paulo. I - Levantamento por fotointerpretação das áreas cobertas com Cerrado, cerradão e campo, em 1962. Bragantia. 24(1):159-172. 
BRANDO, P.M. \& DURIGAN, G. 2004. Changes in Cerrado vegetation after disturbance by frost (São Paulo State, Brazil). Plant Ecol. 175):205-215.

BUCHMANN, M. 2002. Plant ecophysiology and forest response to global change. Tree Physiol. 22(15-16):1177-1184.

CASTRO, A.A.J.F. 1987. Florística e fitossociologia de um Cerrado marginal brasileiro, Parque Estadual de Vaçununga, Santa Rita do Passa Quatro - SP. Tese de Mestrado, Universidade Estadual de Campinas, Campinas, $240 \mathrm{p}$.

CASTRO, A.A.J.F., MARTINS, F.R., TAMASHIRO, J.Y. \& SHEPHERD, G.J. 1999. How rich is the flora of the Brazilian Cerrado? Ann. Miss. Bot. Gard. 86:192-224.

CARVALHO, P.E.R. 2003. Espécies arbóreas brasileiras. Embrapa Informação Tecnológica, Brasília, 1039 p.

COOPER, M., RUGGIERO, P.G.C., SPAROVEK, G. \& PIRES NETO, A.G. 2005. Solos da Gleba Cerrado Pé-de-Gigante. In O Cerrado do Pé-deGigante, Parque Estadual de Vassununga: ecologia e conservação (V. R. Pivello \& E. M. Varanda, eds.). SMA, São Paulo.

CONSERVATION INTERNATIONAL. 2009. Cerrado. Arlington, VA. USA. http://www.conservation.org/explore/priority_areas/hotspots/south_ america/Cerrado/Pa ges/default.aspx (último acesso em 07/01/2010).

COUTINHO, L.M. 1978. O conceito de Cerrado. Rev. Bras. Bot. 1:17-23.

COUTINHO, L.M. 2006. O conceito de Bioma. Acta Bot. Bras. 20(1):1-11.

DURIGAN, G., NISHIKAWA, D.L.L., ROCHA, E., SILVEIRA, E.R., PULITANO, F.M., REGALADO, R.B., CARVALHAES, M.A., PARANAGUÁ, P.A. \& RANIERI, V.E.L. 2002. Caracterização de dois estratos da vegetação em uma área de Cerrado no município de Brotas, SP, Brasil. Acta Bot. Bras. 16(3):251-262.

DURIGAN, G., SIQUEIRA, M.F., FRANCO, G.A.D.C., BRIDGEWATER, S. \& RATTER, J.A. 2003. The vegetation of priority areas for Cerrado conservation in São Paulo State, Brazil. Edinburgh Jour. Bot. 60(2):217-241.

DURIGAN, G., FRANCO, G.A.D.C. \& SIQUEIRA, M.F. 2004. A vegetação dos remanescentes de Cerrado no Estado de São Paulo. In Viabilidade de conservação dos remanescentes de Cerrado no Estado de São Paulo. (M.D. Bittencourt \& R.R. Mendonca, coords.) 1 ed. Annablume, São Paulo, p. 29-56.

EITEN, G. 1963. Habitat flora of Fazenda Campininha, São Paulo, Brazil. In Simpósio sobre o Cerrado. (M.G. Ferri, ed.). EDUSP, São Paulo, p. $157-202$.

FELFILI, J.M., SILVA JUNIOR, M.C., REZENDE, A.V., NOGUEIRA, P.E., WATER, B.M.T., SILVA, M.A. \& ENCINAS, J.I. 1997. Comparação florística e fitossociológica do Cerrado nas chapadas Pratinha e dos Veadeiros. In Contribuição ao conhecimento ecológico do Cerrado (L. Leite \& C.H. Saito, eds.). Universidade de Brasília, Brasília, p. 6-11.

FELFILI, J.M., REZENDE, A.V., SILVA JUNIOR, M.C. \& SILVA, M.A. 2000. Changes in the floristic composition of Cerrado sensu stricto in Brazil over a nine-year period. J. Trop. Ecol. 16(4):579-590.

FELFILI, J.M., NOGUEIRA, P.E., SILVA JUNIOR, M.C., MARIMON, B.S., DELITTI, W.B.C. 2002. Composição florística e fitossociologia do Cerrado sentido restrito no município de Água Boa - MT. Acta Bot. Bras. 16(1):103-112.

FELFILI, J.M., CARVALHO, F.A. \& HAIDAR, R.F. 2005. Manual para o monitoramento de parcelas permanentes: nos Biomas Cerrado e Pantanal. Universidade de Brasília, Brasília, 56 p.

FIDELIS, A.T. \& GODOY, S.A.P. 2003. Estrutura de um Cerrado strico sensu na gleba Cerrado Pé-de-gigante, Santa Rita do Passa Quatro, SP. Acta. Bot. Bras. 17(4):531-539.

FINNIGAN, J. 2004. The footprint concept in complex terrain. Agri. For. Met. 127:117-129.

FRANCO, A.C. 2002. Ecophysiology of woody plants. In The Cerrados of Brazil: ecology and natural history of a neotropical savanna (P.S. Oliveira \& R.J. Marquis, eds.). Columbia University Press, Irvington, p. 178-197.
GOMES, B.Z., MARTINS, F.R. \& TAMASHIRO, J.Y. 2004. Estrutura do cerradão e Da transição entre cerradão e floresta paludícola num fragmento da International Paper do Brasil Ltda., em Brotas, SP. Rev. Bras. Bot. 27(2):249-262.

GRACE, J., JOSE, J.S., MEIR, P., MIRANDA, H.S. \& MONTES, R.A. 2006. Productivity and carbon fluxes of tropical savannas. Jour. Biogeography. 33:387-400.

GROSS, E., CORDEIRO, L. \& CAETANO, F.H. 2002. Nodule ultrastructure and initial growth of Anadenanthera peregrina (L.) Speg. var. falcata (Benth.) Altschul plants infected with rhizobia. Ann. Bot. 90(2): 175-183.

HARPER, T.L. 1977. Population biology of plants. Academic Press, New York.

HENRIQUES, R.P.B. 2005. Influência da história, solo e fogo na distribuição e dinâmica das fitofisionomias no bioma Cerrado. In Cerrado: ecologia, biodiversidade e conservação. (A. Scariot, J.C. Souza Silva \& J.M. Felfili, orgs.). Ministério do Meio Ambiente, Brasília, 439 p.

HENRIQUES, R.P.B. \& HAY, J.D. 2002. Patterns and dynamics of plant populations. In The Cerrados of Brazil: ecology and natural history of a neotropical savanna (P.S. Oliveira \& R.J. Marquis, eds.). Columbia Univeristy Press, New York.

JOLY, C.A., AIDAR, M.P.M., KLINK, C.A., MCGRATH, D.G., MOREIRA, A.G., MOUTINHO, P., NEPSTAD, D.C., OLIVEIRA, A.A., POTT, A., RODAL, M.J.N. \& SAMPAIO, E.V.S.B. 1999. Evolution of the Brazilian phytogeography classification systems: implications for biodiverisity conservation. Ciên. Cult. 51(5/6):331-348.

KÖPPEN, W. 1948. Climatologia. Fondo de Cultura Económica, México. KRONKA, F.J.N., NALON, M.A., MATSUKUMA, C.K., PAVÃO, M., GUILLAUMON, J.R., CAVALLI, A.C., GIANNOTTI, E., IWANE, M.S.S., LIMA, L.M.P.R., MONTES, J., DEL CALI, I.H. \& HAACK, P.G. 1998. Áreas de domínio do Cerrado no Estado de São Paulo. Secretaria de Estado do Meio Ambiente, São Paulo.

LEITÃO-FILHO, H.F. 1992. A flora arbórea dos Cerrados do estado de São Paulo. Hoehnea. 19(1/2):151-163.

LLOYD, J. 1999. The $\mathrm{CO}_{2}$ dependence of photosynthesis, plant growth responses to elevated $\mathrm{CO}_{2}$ concentrations and their interaction with soil nutrient status. II - Temperate and boreal forest productivity and the combined effects of increasing $\mathrm{CO}_{2}$ concentrations and increased nitrogen deposition at a global scale. Funct. Ecol. 13(4):439-459.

LORENZI, H. 1998. Árvores brasileiras: manual de identificação e cultivo de plantas arbóreas do Brasil. 2 ed. Editora Plantarum, Nova Odessa.

MACHADO, R.B., RAMOS NETO, M.B., PEREIRA, P.G.P., CALDAS, E.F., GONÇALVES, D.A., SANTOS, N.S., TABOR, K. \& STEININGER, M. 2004. Estimativas de perda da área do Cerrado brasileiro: relatório técnico. Conservação Internacional, Brasília. www.conservation.org.br/arquivos/ RelatDesmatamCerrado.pdf (último acesso em 07/01/2010).

MALHI, Y., BALDOCCHI, D.D. \& JARVIS, P.G. 1999. The carbon balance of tropical, temperate and boreal forests. Plant Cell Environ. 22(6):715-740.

MAGURRAN, A.E. 1988. Ecological diversity and its measurements. Croom Helm, London.

MARTINS, F.R. 1993. Estrutura de uma floresta mesófila. 2 ed. Universidade Estadual de Campinas, Campinas.

MEYER, H.A. 1952. Structure, growth, and drain in balanced uneven-aged forests. J. Fores. 50(2):85-92.

MIRANDA, A.C., MIRANDA, H.S., LLOYD, J., GRACE, J., FRANCEY, J.A., MCINTYRE, J.R., MEIR, P., RIGGAN, P., LOCKWOOD, R. \& BRASS, J. 1997. Fluxes of carbon, water and energy over Brazilian Cerrado: an analysis using eddy covariance and stable isotopes. Plant Cell Environ. 20(3):315-328.

MISSOURI BOTANICAL GARDEN. 2009. Tropicos. St. Louis. http://mobot. mobot.org/W3T/Search/vast.html (último acesso em 07/01/2010).

MORAES, J.A.P.V. \& PRADO, C.H.B.A. 1998. Photosynthesis and water relations in Cerrado vegetation. In Ecophysiological strategies of 
xerophytic and amphibious plantas in the neotropics (F.R. Scarano \& A.C. Franco, eds.). Oecol. Bras. 4:45-63.

MOREIRA, A.G. 2000. Effects of fire protection on savanna structure in Central Brazil. J. Biogeogr.. 27(4):1021-1029.

MORISITA, M. 1954. Estimation of population density by spacing methods. Mem. Fak. Sci. 1:187-197. (Serie E, biology).

MYERS, N., MITTERMEIER, R.A., MITTERMEIER, C.G., FONSECA, G.A.B. \& KENT, J. 2000. Biodiversity hotspots for conservation priorities. Nature.403 (6772):853- 858.

OLIVEIRA, F.F. \& BATALHA, M.A. 2005. Lognormal abundance distribution ofwoody species in a Cerrado fragment (São Carlos, southeastern Brazil). Rev. Bras. Bot.28(1):39-45.

OLIVEIRA FILHO, A.T., SHEPHERD, G.J., MARTINS, F.R. \& STUBBLENBY,W.H. 1989. Environmental factors affecting physiognomic and floristic variation in an area of Cerrado in Central Brazil. J. Trop. Ecol. 5:413-431.

OLIVEIRA FILHO, A.T. \& RATTER, J.A. 1995. A study of the origin of central brazilians forests by the analysis of plant species distribution patterns. Edinburgh Jour. Bot. 52(2):141-194.

PAULA, N.F. 2002. Capacidade fotossintética, deciduidade e teor de nitrogênio e fósforo em espécies lenhosas do Cerrado. Tese de Doutorado, Universidade Federal de São Carlos, São Carlos.

PIELOU, E.C. 1975. Ecological diversity. John Wiley \& Sons, New York.

PINHEIRO, E.S. 2008. Análises ecológicas e sensoriamento remoto aplicados à estimativa de fitomassa de Cerrado na estação ecológica de Assis, SP. Tese de Doutorado, Universidade de São Paulo, São Carlos, 200 p.

PIRES NETO, A.G., ROCHA, H.R., COOPER, M. \& SHIDA, C.N. 2005 Caracterização física do Cerrado Pé-de-Gigante e uso das terras na região: fisiografia da região. In O Cerrado do Pé-de-Gigante, Parque Estadual de Vassununga: ecologia e conservação (V.R. Pivello \& E.M. Varanda, eds.). SMA, São Paulo.

PIVELLO, V.R., BITENCOURT, M.D., MANTOVANI, W., MESQUITA JUNIOR, H.N., BATALHA, M.A. \& SHIDA, C. 1998. Proposta de zoneamento ecológico para a reserva de Cerrado Pé-de-Gigante (Santa Rita do Passa Quatro, SP). Rev. Bras. Ecol. 2(2):108-118.

PIVELLO, V.R. \& VARANDA, E.M. 2005. O Cerrado do Pé-de-Gigante, Parque Estadual de Vassununga: ecologia e conservação. SMA, São Paulo.

RATTER, J.A. \& DARGIE, T.C.D. 1992. An analysis of the floristic composition of 26 Cerrado areas in Brazil. Edinburgh Jour. Bot. 49:235-250.

RATTER, J.A., RIBEIRO, J.F.L. \& BRIDGEWATER, S. 1997. Brazilian Cerrado vegetation and threats to its biodiversity. Ann. Bot. 80:223-230.

RATTER, J.A., BRIDGEWATER, S. \& RIBEIRO, J.F. 2003. Analysis of the floristic composition of the Brazilian Cerrado vegetation III: comparison of woody vegetation of 376 areas. Edinburgh Jour. Bot. 60(1):57-109.

RIBEIRO, J.F. \& WALTER, B.M.T. 1998. Fitofisionomias do Bioma Cerrado. In Cerrado: ambiente e flora (S.M. Sano \& S.P. Almeida, eds.). EMBRAPA, Planaltina, p. 89-166.

ROCHA, H.F., ROSOLEM, R., JUAREZ, R.N., TANNUS, M.V., LIGO, O.M.R.C. \& DIAS, M.A.F.S. 2002. Measurements of $\mathrm{CO}_{2}$ exchange over a woodland savanna (Cerrado sensu stricto) in southeast Brasil. Biota Neotrop. v2(1):http://www.biotaneotropica.org.br/v2n1/pt/ abstract?article+BN01702012002 (último acesso em 07/01/2010).
ROCHA, H.R., FREITAS, H.C., ROSOLEM, R., TANNUS, R.N., JUAREZ, R.I.N., LIGO, M.A., CABRAL, O.M.R., MESQUITA JUNIOR, H.N. \& BITENCOURT, M.D. 2005. Ciclo hidrológico e microclima. In O Cerrado Pé de Gigante: ecologia e conservação. (V.R. Pivello \& E.M. Varanda, eds.). Imprensa Oficial do Estado de São Paulo, São Paulo, p. 51-60.

SÃO PAULO. Secretaria de Estado do Meio Ambiente. 1997. Bases para a conservação e uso sustentável das áreas de Cerrado do Estado de São Paulo. São Paulo. (Série PROBIO/SP).

SCHMID, H.P. 2002. Footprint modeling for vegetation atmosphere exchange studies: a review and perspective. Agric. For. Meteorol. 113(1-4):159-184.

SCHYMANSKI, S.J., RODERICK, M.L., SIVAPALAN, M., HUTLEY, L.B. \& BERINGER, J. 2007. A test of the optimality approach to modeling canopy properties and $\mathrm{CO}_{2}$ uptake by natural vegetation. Plant Cell Environ. 30(12):1586-1598.

SCHULZE, E.D., LLOYD, J., KELLIHER, F.M., WIRTH, C., REBMANN, C., LÜHKER, B., MUND, M., KNOHL, A., MILYUKOVA, I.M., SCHULZE, W. ZIEGLER, W., VARLAGIN, A.F., SOGACHEV, A.F. VALENTINI, R., DORE, S., GRIGORIEV, S., KOLLE, O., PANFYOROV, M.I., TCHEBAKOVA, N. \& VYGODSKAYA, N.N. 1999. Productivity of forests of the Eurosiberian boreal region and their potential to act as a carbon sink: a synthesis. Global Change Biol. 5(6):703-722.

SERRA FILHO, R., CAVALLI, A.C., GUILLAUMON, J.R., CHIARINI, J.V., NOGUEIRA, F.P., IVANCKO, C.M.A.M., BARBIERI, J.L., DONIZELI, P.L., COELHO, A.G.S. \& BITTENCOURT, I. 1975. Levantamento da cobertura natural e do reflorestamento no Estado de São Paulo. Bol. Tech. Inst. Florestal. 11:1-56.

SHEPHERD, G.J. 1995. Fitopac 1: manual do usuário. Departamento de Botânica, Campinas.

SILBERBAUER-GOTTSBERGER, I. \& EITEN, G. 1983. Fitossociologia de um hectare de Cerrado. Bras. Florestal. 54:55-70.

VEENENDALL, E.M., OLAF KOLLEW, O. \& LLOYD, J. 2004. Seasonal variation in energy fluxes and carbon dioxide exchange for a broad-leaved semi-arid savanna (Mopane woodland) in Southern Africa. Global Change Biol. 10(3):318-328.

VIEIRA, D.L., SCARIOT, A., SAMPAIO, A.B. \& HOLL, K.D. 2006. Tropical dry-forest regeneration from root suckers in Central Brazil. Jour. Trop. Ecol. 22(3):353 357 .

VOURLITIS, G.L., PRIANTE FILHO, N., HAYASHI, M.M.S., SOUSA NOGUEIRA, J., CASEIRO, F.T. \& CAMPELO JUNIOR, J.H. 2001. Seasonal variations in the net ecosystem $\mathrm{CO}_{2}$ exchange of a mature Amazonian tropical transitional forest (cerradão). Funct. Ecol. 15(3):388-395.

WEISER, V.L. \& GODOY, S.A.P. 2001. Florística em um hectare de Cerrado stricto sensu na ARIE - Cerrado Pé-de-gigante, Santa Rita do Passa Quatro, SP. Acta Bot. Bras. 15(2):201-212

WEAVER, W. \& SHANNON, C.E. 1949. The mathematical theory of communication. University of Illinois, Urbana.

Recebido em 12/08/08 Versão reformulada recebida em 19/11/09 Publicado em 01/01/10 